\title{
RECONSTRUCTION AND TOWN AND COUNTRY PLANNING
}

$\mathrm{T}$ HE widespread destruction of property in the Greater London area which has attended the air raids of recent weeks should have brought home to everyone both the need and the opportunity for reconstruction which have come. The appointment of Sir John Reith, who is being made a baron, to the new office of Minister of Works and Buildings and First Commissioner of Works, suggests that the Government recognizes officially the magnitude of the task which lies ahead. So long ago as November 1939 an admirable paper by W. Braxton Sinclair on A.R.P. in town planning before the Air Raid Protection Institute indicated some of the possibilities in this direction if realistic and rational planning receives the executive authority to ensure that the plans are given appropriate effect.

The reconsideration of the planning of London in the light of civil defence is, however, only one point of view which needs attention before reconstruction is undertaken. Other important factors were indicated in the P E P (Political and Economic Planning) report on the location of industry and have since been reiterated in the report of the Royal Commission on the Geographical Distribution of the Industrial Population. Attention has recently been directed to the importance of this report by Lord Balfour of Burleigh, chairman of the 1940 Council, appointed by a conference of the Royal Institute of British Architects in February of this year for the promotion of the planning of social environment.

The conference in question was called to consider whet immediate action could be taken to promote, through research groups or by other means, the planning of social environment on a national scale and to make more widely known the need for such planning. The work of the Council thus involves both research and publicity, and its activity in each field will be largely dependent on interested societies, the co-operation of which will be sought in their special fields of work. Lord Balfour has emphasized the way in which planning for postWar conditions must start from the recommendations of the Report of the Barlow Commission, and has also indicated the Council's general agreement with nine agreed points of principle reached by the Royal Commission. Beyond this, however, the Council recommends further investigations in a number of directions, particularly as there appears to be no immediate prospect of the proposed national board being established.
Among these new directions for investigation as a prelude to reconstruction are the problems raised by evacuation and the dispersal of industry, through the development in rural areas and elsewhere of immense war industries and undertakings. There are also the problems already mentioned arising from the destruction of buildings by aerial bombardment, and those of planning for demobilization so as to have ready for immediate operation a long-term constructive programme to bring hope and inspiration to a war-weary people, millions of whom will see their war occupations eoming to an end. Lord Balfour rightly suggests that such problems may well call for a different type of national board from that envisaged by the Royal Commission, and that in view of the extent to which the winning of the War demands almost the entire attention of the Government, the preliminary research and thought should be devoted to these problems by a voluntary body such as the 1940 Council.

There is ample evidence that Lord Balfour of Burleigh's initiative is not premature, even if we are at the height of a life-and-death struggle. Valuable, however, as the efforts of an unofficial body may be, there are several reasons for doubting whether anything short of an official body will be adequate even for the preliminary work. For one thing, apart from the fairly considerable amount of research that will be required, the whole course of the War demonstrates the difficulty of predicting its termination with any exactitude. The fundamental lines of our planning can scarcely be determined too early if they are to be ready against an unexpectedly early termination of hostilities, the demands of which are likely to be no less searching than at the end of a prolonged struggle. Moreover, as the War proceeds, the problems in which immediate action affecting post-War policy and planning are imperative multiply. Not only does it frequently happen that the wisest immediate policy is that in line with long-range requirements of reconstruction, but also in the absence of such foresight fresh obstacles may be created or allowed to grow up in the way of the planning required on a national scale after the War.

The whole experience of the War of 1914-18 goes to show indeed that planning for reconstruction during a war is essential. The Ministry of Reconstruction which was created in August 1917 was actually the successor of a Reconstruction Committee appointed much earlier by Mr. Asquith 
when still Prime Minister. The great value of the plans prepared by the Ministry before the Armistice is often obscured by the difficulties which appeared in 1920. Much social legislation of which we are now justly proud was embodied in those plans. While other projects encountered heavy weather either temporarily or permanently, it is quite clear that but for the work of the Ministry of Reconstruction our post-war troubles of 1919 onward would have been even more serious. So far from the formation of the Ministry being premature the evidence is rather that it was not initiated early enough for all the complex problems involved to be investigated adequately before it was necessary to formulate policy and take action.

The scope of the work and duties of the Ministry of Reconstruction as conceived after some six months work are well worth recalling at the present time. A statement issued to the Press for a meeting on January 24,1918 , indicates that the Ministry embraced branches dealing with commerce and production, including the supply of materials; with finance, shipping and common service; with labour and industrial organization ; with rural development; with the machinery of Government, central and local, including health and education; and with housing and internal transport. The Ministry as a whole and the several branches in particular were concerned with the study of all proposals for dealing with post-War problems, whether under consideration by Government departments or committees or advanced by responsible bodies or persons, and with the development out of this material of a reasoned policy of reconstruction in all its branches. An advisory council, representative of all the leading interests concerned, had already been created by the Minister, organized in four sections on similar lines, and the statement indicates that in certain fields inquiry had already reached a surprisingly advanced stage.

Much of the work which was done then is clearly available for our guidance in the situation confronting us to-day, but whether or not the many investigations which are still required are prosecuted under private or Government auspices, the importance of some co-ordinating Government department charged with the prime responsibility for reconstruction can scarcely be denied. Already the difficulties in regard to relief accommodation and transport, the provision of shelters and the organization of evacuation of non-essential classes from threatened areas have indicated the need for some single supreme authority to deal with these problems in respect of London alone. Such an authority is needed partly to prevent confusion through divided responsibility or inadequate local resources in individual boroughs. Much more, however, the need is for inspiration and leadership and the power to cut through any network of 'red tape' or private interest that may stand in the way of swift emergency provision for the homeless or distressed, or the organization of shelters and transport services so as to secure the maximum possibility of sleep for London's workers.

If a leader of the right type could be found for such a post and given the sweeping powers essential, he could give new spirit and purpose to the whole work and quickly win the eager co-operation of the public. Nor should the effect be confined merely to relief of the immediate strain that the people of London are enduring. The disappearance of difficulties that at present seem formidable in the immediate situation would be of immense value also in dealing with reconstruction after the War, and leadership of the type visualized would supply exactly the right drive and direction required in the approach to problems of reconstruction during the War.

What seems to emerge from a review of the work and achievements of the former Ministry of Reconstruction is first that the educational work in preparation for reconstruction was insufficiently thorough and widespread, and secondly, that without disparaging the vision displayed by the Ministry, the importance of co-ordination and the extent to which problems of reconstruction are interlocked was not sufficiently realized. The first of these functions is one that the 1940 Council has undertaken to serve, but the second is undoubtedly one for the Government itself. Moreover, it cannot be expected that all the fundamental research which is required as a basis for planning can wisely be left to individual initiative. Government support and direction are required if only to see that resources are allocated to such effort as part of our national War effort, and in due proportion with other demands.

It is true, of course, that in some directions research is already proceeding under Government auspices, for example, under the Building Research Board, which is of direct importance to post-War planning although inspired by immediate requirements. Much more is possible in this way if only we are awake to our opportunities. For example, it has been pointed out how in the planning of a new city the incorporation of an appropriate green belt can be made to fulfil a military need to enclose and limit the city boundaries and provide dual encircling road communications with ample scope for the provision of aerodromes, anti-aircraft gun positions, searchlight stations and the like, and also accord with the principles of good civil planning. Similarly, in the provision of perfect road communications the military requirements 
coincide in the main with the civil needs of the population.

While it is true that in town planning, as well as in regard to building, we need principles which have been reached as a result of scientific research, it should not be forgotten that in particular scientific fields a firm scientific basis is already available as a basis for policy. What is required in the matter of sunlight incidence, for example, as pointed out by Mr. Thomas Sharp in his excellent little volume on "Town Planning" in the Pelican series, is appropriate action on the facts already ascertained. The most disturbing feature of the whole situation is indeed just the shelving by the Government of the Report of the Barlow Commission.

It cannot be too strongly insisted that unless the long-term problems involved in the location of industry, evacuation, and national defence are faced now, formidable and perhaps unsurmountable obstacles may be placed in the way of the scientific use of our resources and of post-War reconstruction. Town and country planning have acquired a new importance, and the formulation of a national policy is imperative.

For this reason alone Mr. Sharp's little book deserves widespread attention. It is not merely that he directs attention to the dangers attending a policy of drift or to the essential unity of town and country planning. He stresses the need for a clearly thought out and well-defined policy, but the greatest value of his book may well lie in the revelation it will bring to many of the opportunities which clear vision and determined policy can put within our reach.

It is indeed important to remember those opportunities in view of the triviality and narrowness of some of the aims of our statutory town and country planning, its inadequacy or ineffectiveness, particularly on the larger issues, in face of the rights of private property, and the inadequacy of the agents to which such planning has hitherto been entrusted. It should be remembered, moreover, that the English contribution to the art of building towns was once an original and a valuable one, while its achievement in the countryside in the eighteenth century, as Mr. Sharp points out, was one of the most successful creations of its kind in the contemporary world.

The knowledge of the way in which the opportunities for improvement which changing conditions offered was taken by our eighteenth century forefathers should be an inspiration to us amid the even greater opportunities of to-day. If we vigorously seize them, snatching from them every possibility of doing our work in the finest instead of the easiest way, we may not only find new forms of expression worthy of the new materials and new powers with which science and technical advance have endowed us, but also, in so doing, once again build towns that will be worthy of us, possessing beauty and order and all the facilities for the living of that good social and physical life which it is the prime purpose of the town to provide.

Simultaneously, the opportunities in the countryside must be recognized and used. The preservation of the countryside must be recognized as a dynamic, not a static, ideal. The countryside is not merely scenery; it is a place of industry as much as is the town, a place of social and economic activity. It is a living organism to preserve which is merely to kill it.

No less in the countryside than in the town, we can if we will use the opportunities of social and economic change for the creation of new beauties and new possibilities of happiness: Already the problems encountered in evacuation have indeed shown how much might yet be done to make an even finer countryside in which, beside the harmony of all its constituents in a sympathetic relationship to each other, making a splendid whole which was the feature of the past, we have among those constituents the facilities necessary to enable the great new inventions to confer their immense benefits upon the countryside as well as on the town. Besides this, the exploration of agricultural policy in regard to food supply and health may well lead to new lines of development, to changes in the use of the land which have to be integrated into a national rather than a departmental policy if we are to reap their full benefits.

It is well that the opportunities which are before us should be so clearly indicated, and the extent to which we can, if we will, seize them while still prosecuting our War effort with all the energy at our command. Our environment will be modified by new forms of knowledge as well as by the demands of national defence or the consequences of enemy action, whether we consciously use that new knowledge in planning or not. The full advantages of social and economic reconstruction can only be secured if we embark now on the necessary planning and the investigations on which such planning must be based. If we attempt at once to take full account of the impact upon town and country planning and social conditions of the revolution in means of communication, and so plan the utilization of our resources for national defence that post-War reconstruction is kept clearly in mind, it should be possible to avoid many sacrifices of the requirements of peaceful living, to promote that educational process which must precede social reconstruction and to foster much of the scientific research which will supply the basic data alike for the purposes of total war and for the reconstruction to follow. 